\title{
Differential associations between psychosocial stress and obesity among Ghanaians in Europe and in Ghana: findings from the RODAM study
}

\author{
Clarissa Baratin ${ }^{1,2} \cdot$ Erik Beune $^{1} \cdot$ Daan van Schalkwijk ${ }^{2} \cdot$ Karlijn Meeks $^{1} \cdot$ Liam Smeeth $^{3} \cdot$ Juliet Addo $^{3}$. \\ Ama de-Graft Aikins ${ }^{4}$. Ellis Owusu-Dabo ${ }^{5}$. Silver Bahendeka ${ }^{6}$. Frank P. Mockenhaupt ${ }^{7} \cdot$ Ina Danquah $^{8,9}$. \\ Matthias B. Schulze ${ }^{8} \cdot$ Joachim Spranger $^{10,11}$ • Daniel Boateng ${ }^{12} \cdot$ Kerstin Klipstein-Grobusch $^{12,13} \cdot$ Karien Stronks $^{1}$. \\ Charles Agyemang ${ }^{1}$
}

Received: 23 June 2018 / Accepted: 25 February 2019 / Published online: 11 March 2019

(c) The Author(s) 2019

\begin{abstract}
Purpose Psychosocial stress is associated with obesity in some populations, but it is unclear whether the association is related to migration. This study explored associations between psychosocial stress and obesity among Ghanaian migrants in Europe and non-migrant Ghanaians in Ghana.

Methods Cross-sectional data from the RODAM study were used, including 5898 Ghanaians residing in Germany, the UK, the Netherlands, rural Ghana, and urban Ghana. Perceived discrimination, negative life events and stress at work or at home were examined in relation to body mass index (BMI) and waist circumference (WC). Linear regression analyses were performed separately for migrants and non-migrants stratified by sex.

Results Perceived discrimination was not associated with BMI and WC in both migrants and non-migrants. However, negative life events were positively associated with BMI $(\beta=0.78,95 \%$ CI $0.34-1.22)$ and WC $(\beta=1.96,95 \%$ CI $0.79-3.12)$ among male Ghanaian migrants. Similarly, stress at work or at home was positively associated with BMI $(\beta=0.28,95 \%$ CI 0.00-0.56) and WC ( $\beta=0.84,95 \%$ CI 0.05-1.63) among male Ghanaian migrants. Among non-migrant Ghanaians, in contrast, stress at work or at home was inversely associated with BMI and WC in both males $(\beta=-0.66,95 \% \mathrm{CI}-1.03$ to $-0.28 ; \beta=-1.7195 \% \mathrm{CI}-2.69$ to -0.73 , respectively) and females $(\beta=-0.81,95 \% \mathrm{CI}-1.20$ to $-0.42 ; \beta=-1.46$, $95 \% \mathrm{CI}-2.30$ to -0.61 , respectively).

Conclusions Negative life events and stress at work or at home are associated with increased body weight among male Ghanaians in European settings, whereas stress at work or at home is associated with reduced body weight among Ghanaians in Ghana. More work is needed to understand the underlying factors driving these differential associations to assist prevention efforts.
\end{abstract}

Keywords Ghana $\cdot$ Migration $\cdot$ Stress $\cdot$ Life events $\cdot$ BMI

\section{Introduction}

Over the past 40 years, the number of obese people has grown exponentially, surpassing the number of underweight people in the world [1]. This shows the extent to which obesity has become a global concern, and emphasizes the importance of understanding its underlying causes

Charles Agyemang

c.o.agyemang@amc.uva.nl

Extended author information available on the last page of the article and identifying at-risk populations to limit its health-related complications. In Europe, migrant and ethnic minority populations have been shown to suffer more from obesity and its consequences such as type 2 diabetes than the general European populations [2, 3]. Sub-Saharan African (SSA) migrants, one of the most rapidly increasing migrant communities in Europe, are among the most affected by both obesity and type 2 diabetes [4-9]. However, understanding the role of migration on obesity rates among SSA migrants requires comparing migrants with the population of their country of origin [10]. The RODAM study did this by performing a cross-sectional analysis of Ghanaians living in 
Europe (the Netherlands, Germany, and UK) and Ghana [5]. Results revealed that both female and male Ghanaian migrants in Europe were significantly more obese than nonmigrants in Ghana [5].

While the specific ways in which migration affect obesity remain unclear, current studies point towards a complex interplay of factors influencing energy intake and expenditure $[2,7,11]$. In migrant populations, whose genetic profiles are similar to their non-migrant peers, a literature review by Misra and Ganda concluded that the contextual changes due to migration, combined with their cultural and socioeconomic background, can change their lifestyle and introduce stress, which may contribute to obesity [2]. Indeed, upon migration, migrants are exposed to a high number of new psychosocial stressors. A qualitative study of Ghanaian migrants in the Netherlands showed that they were affected by economic and social pressures from their homeland, which were associated with high levels of perceived stress [12]. Furthermore, these migrants cited "adapting to Dutch society" as a source of stress and health problems [12]. Migrants face barriers such as financial issues with debts and taxes, insecurity, and job stressors, which can all lead to stress $[13,14]$. Further recurrent psychosocial stressors among migrants in Europe have been attributed to racial discrimination and lack of social support $[8,15]$. Considering that stress has been identified as a risk factor for obesity $[2,7,11]$, the change in environmental stressors could potentially explain the high rates of obesity within migrant populations. This relationship between psychosocial stress and health outcomes among migrants may differ compared with the population of their country of origin who did not migrate, since both groups are exposed to different contexts. However, associations between stress and obesity may also differ within the migrant population, considering that the structural, socioeconomic background and cultural factors are dynamic, intersecting processes, which work together with other factors, in particular gender, to shape migrant experiences [16]. Therefore, this study aimed to examine the associations between stress and obesity across settings and genders, among Ghanaian migrants in Europe compared to non-migrants in Ghana.

For the purpose of this study, stress is defined as the result of an imbalance between an individual's environmental demands, or "stressors", and their available resources to cope with these demands [17-19]. In the case where stressors exceed a person's coping resources, stress is perceived by the individual, which activates a stress response that may later lead to a distressed condition such as depression [17-20]. From a physiological viewpoint, the stress response involves the release of glucocorticoids from the hypothalamus, which are ultimately able to alter both appetite regulation and metabolism thus leading to weight gain [21-25]. Additionally, stress has been shown to increase preference for energy-dense foods while decreasing physical activity, leading to increased body weight, and, subsequently, increased prevalence of overweight and obesity [26-28]. Despite this physiological evidence, epidemiological studies examining the relationship between stress and obesity have not produced consistent results [29]. A meta-analysis of 14 cohort studies from around the world revealed that, although higher stress did generally promote weight gain, $69 \%$ of analyses showed no association between stress and adiposity [29]. However, this meta-analysis was limited by the lack of a consistent measure of stress: different stressrelated measures, from job dissatisfaction and caregiver stress to negative life changes, were used in each study [29]. This variance can be partly explained by the fact that stress is an intricate concept which is difficult to define objectively, as it is directly linked to very different stressors such as job stress, negative life events, or discrimination, but also coping resources and distressed reactions elicited such as depression [30]. However, this also means that restricting stress to only one of its aspects, as done in many studies of the meta-analysis, may conceal some of its effects on health. Additionally, the findings were further complicated by the different populations examined in each study, for whom stress may not be experienced in the same ways [30]. Indeed, as explained previously, contextual differences between populations may entail different environmental stressors and interactions with these stressors, which could potentially lead to differential associations of stress and obesity. Therefore, the inconsistent results of the meta-analysis highlight the importance of using multiple stress measures and exploring associations across settings when different contexts are involved.

This study focused on psychosocial stress including perceived discrimination, negative life events, and perceived stress at home or at work to explore their associations with obesity among Ghanaian migrants in Europe and nonmigrants in Ghana. Two research questions in particular were addressed:

1. Are psychosocial stress factors associated with obesity in Ghanaian migrants and their non-migrant peers?

2. Does the association of psychosocial stress factors with obesity in Ghanaian migrants differ from their nonmigrant peers?

\section{Methods}

\section{Study population}

The Research on Obesity and Diabetes among African Migrants (RODAM) study data were used for this study. Full details of the study aims, design and methods have been published previously [5, 7]. In brief, RODAM is a multi-centre 
cross-sectional study, which was performed between 2012 and 2015 with the aim of uncovering the causes of high obesity and type 2 diabetes prevalence among SSA migrants in Europe. The sample consists of Ghanaian adults between the ages of 25 and 70-year-old, residing in five different locations: rural and urban Ghana (Ashanti region), Germany (Berlin), UK (London), and the Netherlands (Amsterdam). Recruitment strategies differed slightly per location, due to differences in population registration systems. In Ghana, a random sampling procedure was used to select 15 rural census enumeration areas and two cities in the Ashanti region. Team members then organized local mini-clinics to collect data within the communities. In Berlin and London, individuals were randomly drawn from member lists of Ghanaian churches and organizations. In Amsterdam, Ghanaian individuals were identified and randomly selected from the Amsterdam Municipal Health register. In all European sites, selected individuals received written invitations. The participation rates differed across locations: $76 \%$ in rural Ghana, 74\% in urban Ghana, $68 \%$ in Berlin, $75 \%$ in London, and $53 \%$ in Amsterdam. Before implementation, the project was approved by ethics committees in all sites and all participants gave written consent.

Data were collected through a physical examination and a structured questionnaire administrated via interview, paper, or digitally, based on the preference of the participant. Interviewers had a Ghanaian background, received specific training, and were instructed to conduct interviews in the preferred language of the participant. The questionnaire contained information on demographics, migration history, socioeconomic status, health status, and a psychosocial section including subparts for "recent well-being (depression)", "perceived discrimination", "recent experiences (negative life events)", and "perceived psychological stress at work or at home". The physical examination assessed a series of anthropometric measurements performed twice on each participant by the same examiner. Weight was measured to the nearest $0.1 \mathrm{~kg}$ and height to the nearest $0.1 \mathrm{~cm}$. BMI calculation was based on weight $(\mathrm{kg})$ divided by squared height $\left(\mathrm{m}^{2}\right)$. Waist circumference (WC) was measured twice in centimetres (via measuring tape) and the average of both measurements was reported. Data collection methods were identical in all locations, using validated devices according to standard operating procedures.

\section{Dependent variables}

The dependent variables of this study were BMI and WC. BMI was chosen for being the most commonly used indicator of adiposity and thus easily comparable to other studies, while WC is thought to be more strongly associated with health risks in SSA populations [29, 31]. Obesity in terms of BMI was defined as per WHO standards as a BMI $\geq 30 \mathrm{~kg} /$ $\mathrm{m}^{2}$ [32]. Abdominal obesity was categorized according to WHO cutoffs for substantially elevated risks: waist circumference $>88 \mathrm{~cm}$ in women and $>102 \mathrm{~cm}$ in men [32].

\section{Independent variables}

In this study, the independent variables were psychosocial stress factors that assessed perceived discrimination, perceived stress at work or at home, and negative life events.

\section{Perceived discrimination}

Perceived everyday discrimination, which refers to routinely experienced and often subtle instances of unfair treatment, was measured using an adapted version of the Everyday Discrimination Scale (EDS) [33, 34] (Appendix 1). This 9-item scale asked participants to rate the frequency with which they experience daily mistreatment, such as being treated with less courtesy or less respect, receiving poorer service than other people or being called names or insulted. Participants could rate each of the nine items from "never" $=1$ to "very often" $=5$, and scores were summed and averaged to obtain a final score of $1-5$, with five indicating very frequent perceived discrimination. The EDS, which is one of the most commonly used self-reported discrimination scales [35], has consistently demonstrated high reliability across a variety of ethnicities [36, 37], including African migrants in the Netherlands [38].

\section{Perceived stress at work or at home}

Perceived stress at work or at home was defined as "feeling irritable, filled with anxiety, or as having sleeping difficulties as a result of conditions at work or at home", and was measured by a psychological stress scale created by the INTERHEART study [30] (Appendix 2). Participants were asked two questions, about stress prevalence at work and at home, and could answer "never", "some periods", "several periods", or "constantly". Both answers were then combined into a general score, graded into four categories: never experienced stress, experienced some periods of stress at home or at work, experienced several periods of stress at home or at work, and experienced permanent stress at home or at work [30].

\section{Negative life events}

To measure the presence of major negative life events that could cause acute stress to an individual, the widely-used and well-validated List of Threatening Experiences (LTE) was applied [39, 40]. This list typically asks participants whether they have, in the past 12 months, experienced any of a series of 12 unpleasant events, although a slightly-altered 
version consisting of nine items was used in RODAM for clarity purposes (Appendix 3). Subjects were dichotomized into "no negative life events" (coded as 0 ) and "one or more event" (coded as 1) and participants in the second category were expected to have higher levels of stress.

\section{Covariates}

Covariates assessed were sex, age, socioeconomic status (education), marital status, depressive symptoms, and migration-related factors (migration generation, length of stay in Europe in years, cultural orientation). Education had four levels, ranging from "never been to school or elementary schooling only" to "higher vocational schooling or university". Marital status contained two categories, subjects being either "married/in a registered partnership" or "not married". Depressive symptoms were assessed using the standard, well-validated, and self-administered Patient Health Questionnaire (PHQ-9) [41]. A cutoff of $\geq 10$ points was used to identify significant depressive symptoms; this threshold is considered optimal in terms of sensitivity and specificity, and represents moderate depression [41]. Migration generation, length of stay and cultural orientation were assessed for Ghanaian migrants only. Migration generation was defined based on country of birth, with first-generation migrants born in Ghana and second-generation migrants born in Europe from Ghanaian parents. Cultural orientation was measured using an adapted version of the Psychological Acculturation Scale (PAS) developed by Tropp et al. [42]. Specifically, migrants were asked to rate their agreement with ten statements regarding their attachment to British, Dutch, and German culture on a 5-point Likert scale in the three European countries. Results were then averaged and categorized into "less acculturation" and "more acculturation". Length of stay was defined as the number of years lived in Europe, at the time of data collection. Both variables were adjusted for due to evidence suggesting that they influence mental health [43-45].

\section{Statistical analysis}

Baseline statistics were reported as either the mean and standard deviation (mean $\pm \mathrm{SD}$ ) or median and interquartile range [median (IQR) for continuous variables, depending on skewness; count and percentage $(n(\%)]$ were used for categorical variables. Tests were carried out separately for migrants and non-migrants. To compare both populations, the $t$ test and independent samples median test were used, for mean values and medians, respectively. Interactions between sex and psychosocial stress (sex*psychosocial stress factor) as well as site (Europe or Ghana) and psychosocial stress (site*psychosocial stress factor) were assessed in linear regression models for both BMI and WC. Since they were significant, associations between psychosocial stress factors (perceived discrimination, stress at work and at home, negative life events) and obesity (BMI and WC) were presented by sex and site. Furthermore, for each analysis performed, participants with missing data for any of the variables included were excluded from the analysis. The number of missing values was very low for sex, age, BMI and WC ( $<2 \%$ in Europe and Ghana).

Associations between psychosocial stress factors and obesity (BMI and WC) were determined by linear regression models, which were used separately for each psychosocial stress measure in relation to BMI and then in relation to WC. Model 1 consisted of the psychosocial stress measure in question, with adjustment for age. Model 2 was further adjusted for educational level as a potential confounder. Additionally, we adjusted for depressive symptoms in model 3 , as a potential intermediate factor. Model 4 was only applicable to migrants, and further adjusted for migration generation, and length of stay in Europe in years. In all models, perceived discrimination and stress at home or at work were treated as continuous variables, with a score from 1 (never experienced discrimination) to 5 (very frequently perceived discrimination) for the former and 1 (never experienced stress) to 4 (permanent stress at work/home) for the latter. Results were described as unstandardized $\beta$-coefficients with corresponding $95 \%$ confidence intervals and $p$ values. All $p$ values were considered significant at the 0.05 level. All analyses were carried out using SPSS 24.0 for Mac.

\section{Results}

\section{General study population characteristics}

A total of 3332 Ghanaians in Europe and 2566 Ghanaians in Ghana were included in this analysis. Their general characteristics are reported in Table 1, by sex and place of residence. Overall, $41.3 \%(n=1377)$ of the migrant group and 33.2\% $(n=852)$ of the non-migrant group were males. Among males, the mean age was 46.4 years for the migrant population, and 47.5 years for the non-migrants. Among females, the mean age was 45.2 years for migrants, and 46.2 years for non-migrants. Migrants were more highly educated than non-migrants, with $21.9 \%$ of male migrants having achieved the highest level of education compared with $7.9 \%$ of nonmigrants $(p<0.001)$, and $12.1 \%$ of female migrants compared with $2.4 \%$ of non-migrants $(p<0.001)$. Contrarily, a lower number of migrants were married or in a registered partnership compared to non-migrants, for both males (46.2\% versus $69.2 \% ; p<0.001)$ and females $(34.5 \%$ versus $51.0 \%$; $p<0.001)$. Most of the Ghanaians in Europe were first-generation migrants (97.9\% for males and $96.4 \%$ for females) and had migrated 17.1 years ago on average for males and 17.4 for females. Observed levels of acculturation were high, 
Table 1 General study population characteristics

\begin{tabular}{|c|c|c|c|c|c|c|}
\hline \multirow{3}{*}{ Age (years), mean \pm SD } & \multicolumn{3}{|l|}{ Males $(n=2229)$} & \multicolumn{3}{|l|}{ Females $(n=3669)$} \\
\hline & Migrants $(n=1377)$ & $\begin{array}{l}\text { Non- } \\
\text { migrants } \\
(n=852)\end{array}$ & $p$ value & Migrants $(n=1955)$ & $\begin{array}{l}\text { Non- } \\
\text { migrants } \\
(n=1714)\end{array}$ & $p$ value \\
\hline & $46.4 \pm 11.3$ & $47.5 \pm 13.4$ & 0.041 & $45.2 \pm 10.8$ & $46.2 \pm 12.6$ & 0.010 \\
\hline Education, $n(\%)$ & & & $<0.001$ & & & $<0.001$ \\
\hline 1 (lowest) & $165(13.0)$ & $270(33.7)$ & & 487 (27.6) & $957(58.4)$ & \\
\hline 2 & $498(39.3)$ & $329(41.0)$ & & $639(36.2)$ & $536(32.7)$ & \\
\hline 3 & $327(25.8)$ & $140(17.5)$ & & $426(24.1)$ & $107(6.5)$ & \\
\hline 4 (highest) & $278(21.9)$ & $63(7.9)$ & & $213(12.1)$ & $40(2.4)$ & \\
\hline Marital status, $n(\%)$ & & & $<0.001$ & & & $<0.001$ \\
\hline Not married & $665(53.8)$ & $247(30.8)$ & & $1134(65.5)$ & $800(49.0)$ & \\
\hline Married/registered partnership & $570(46.2)$ & $555(69.2)$ & & $596(34.5)$ & $834(51.0)$ & \\
\hline Migration generation, $n(\%)$ & & & - & & & - \\
\hline First & $1233(97.9)$ & - & & $1705(96.4)$ & - & \\
\hline Second & $26(2.1)$ & - & & $63(3.6)$ & - & \\
\hline Length of stay in Europe (years), mean \pm SD & $17.1 \pm 9.7$ & - & - & $17.4 \pm 9.4$ & - & - \\
\hline Cultural orientation & & & - & & & - \\
\hline Less acculturated & $273(22.8)$ & - & & $427(25.4)$ & - & \\
\hline More acculturated & $922(77.2)$ & - & & $1252(74.6)$ & - & \\
\hline Significant depressive symptoms, $n(\%)$ & $76(6.3)$ & $35(4.4)$ & 0.072 & $139(8.2)$ & $95(5.8)$ & 0.008 \\
\hline $\operatorname{BMI}\left(\mathrm{kg} / \mathrm{m}^{2}\right)$, mean $\pm \mathrm{SD}$ & $26.9 \pm 3.9$ & $22.4 \pm 3.8$ & $<0.001$ & $30.1 \pm 5.2$ & $26.2 \pm 5.6$ & $<0.001$ \\
\hline Obesity $\geq 30 \mathrm{~kg} / \mathrm{m}^{2}, n(\%)$ & $253(18.4)$ & $33(3.9)$ & $<0.001$ & $930(47.8)$ & $401(23.4)$ & $<0.001$ \\
\hline Waist circumference $(\mathrm{cm})$, mean $\pm \mathrm{SD}$ & $92.2 \pm 11.1$ & $80.7 \pm 10.2$ & $<0.001$ & $95.1 \pm 12.5$ & $88.3 \pm 12.2$ & $<0.001$ \\
\hline $\begin{array}{l}\text { Abdominal obesity } \geq 88 \mathrm{~cm} \text { (women), } \geq 102 \text { (men), } \\
n(\%)\end{array}$ & $224(16.4)$ & $20(2.3)$ & $<0.001$ & $1381(71.0)$ & $813(47.5)$ & $<0.001$ \\
\hline Perceived discrimination, mean \pm SD & $2.0 \pm 0.8$ & $1.3 \pm 0.4$ & $<0.001$ & $1.8 \pm 0.8$ & $1.3 \pm 0.5$ & $<0.001$ \\
\hline Perceived stress at work/home, $n(\%)$ & & & $<0.001$ & & & $<0.001$ \\
\hline Never & $602(49.6)$ & $243(30.6)$ & & $823(48.1)$ & $462(28.3)$ & \\
\hline Some periods & $464(38.3)$ & $432(54.3)$ & & $609(35.6)$ & $897(55.0)$ & \\
\hline Several periods & $102(8.4)$ & $105(13.2)$ & & $209(12.2)$ & $247(15.2)$ & \\
\hline Permanent & $45(3.7)$ & $15(1.9)$ & & $69(4.0)$ & $24(1.5)$ & \\
\hline Any negative life events over the last 12 months, $n(\%)$ & $726(59.6)$ & $555(69.8)$ & $<0.001$ & $1001(58.3)$ & $1109(68.0)$ & $<0.001$ \\
\hline
\end{tabular}

$S D$ standard deviation

with $77.2 \%$ of males and $74.6 \%$ of females reporting higher levels of acculturation. A similar number of migrant and nonmigrant males were affected by depressive symptoms $(6.3 \%$ versus $4.4 \% ; p=0.072)$. Among females, this number was higher in migrants than in non-migrants $(8.2 \%$ versus $5.8 \%$; $p=0.008$ ). In terms of body indices, the BMI of migrants was on average $26.9 \mathrm{~kg} / \mathrm{m}^{2}$ for males and $30.1 \mathrm{~kg} / \mathrm{m}^{2}$ for females, which is significantly higher $(p<0.001)$ than the BMI of nonmigrants, which was $22.4 \mathrm{~kg} / \mathrm{m}^{2}$ for males and $26.2 \mathrm{~kg} / \mathrm{m}^{2}$ for females. A significantly greater proportion of migrants was obese compared with their non-migrant counterparts, for both males $(18.4 \%$ versus $3.9 \% ; p<0.001)$ and females $(47.8 \%$ versus $23.4 \%$, respectively; $p<0.001)$. These results were consistent with abdominal obesity: the average waist circumference of migrants ( $92.2 \mathrm{~cm}$ for males and 95.1 for females) was significantly higher $(p<0.001)$ than non-migrants (80.7 for males and 88.3 for females), as was the proportion of migrants with abdominal obesity ( $16.4 \%$ for males and $71.0 \%$ for females) compared to non-migrants ( $2.3 \%$ for males and $47.5 \%$ for females).

\section{Psychosocial stress measures and obesity}

Associations of each psychosocial stress factor with BMI and WC are reported in Table 2, by place of residence and sex.

\section{Perceived discrimination}

Ghanaian migrants reported more perceived discrimination than non-migrants. However, no significant association was 


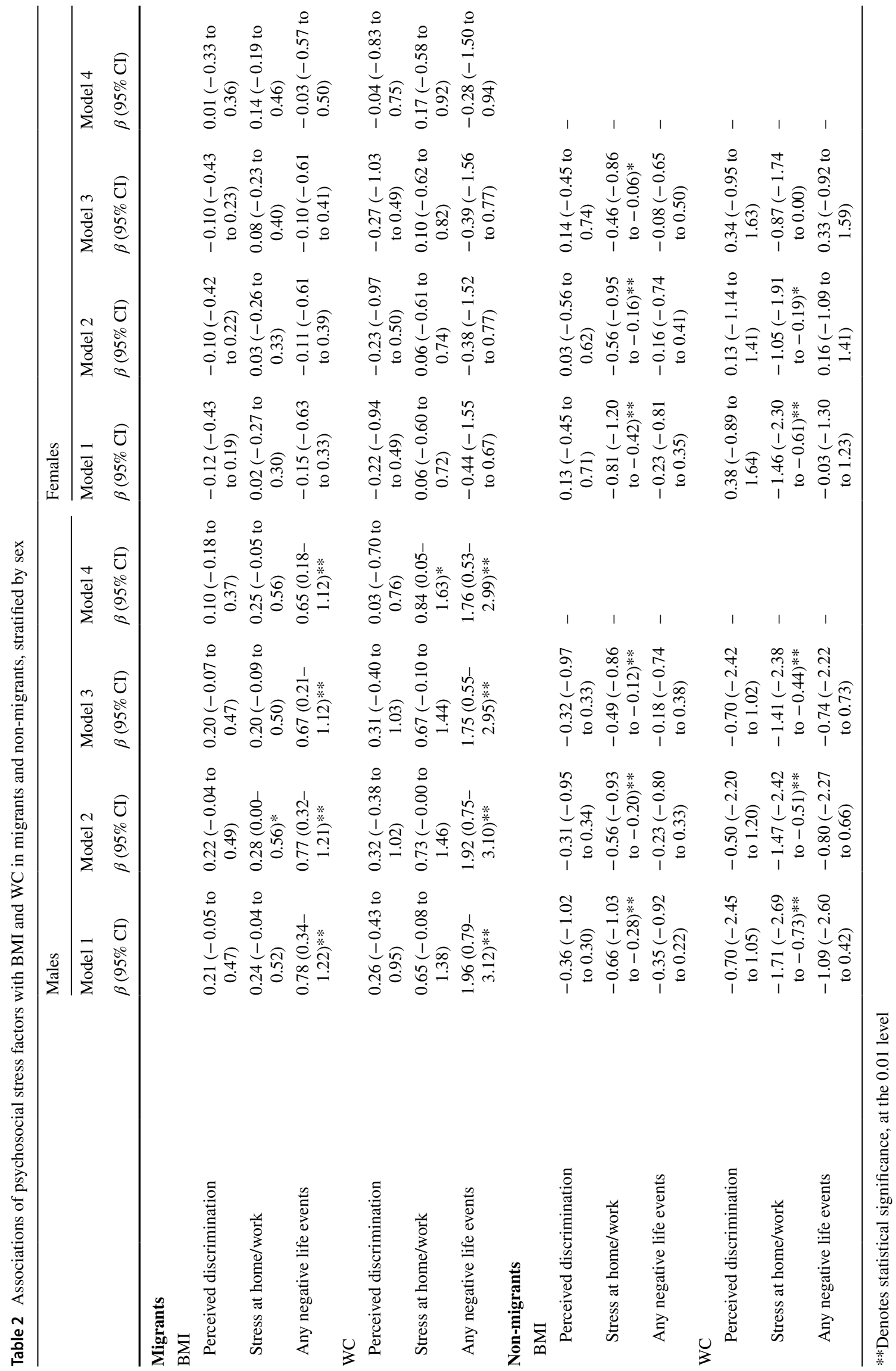


found between perceived discrimination and BMI or WC, even after further adjusting for other factors.

\section{Perceived stress at work or at home}

Male and female migrants reported higher rates of permanent stress (3.7\% versus $1.9 \%$ for males and $4.0 \%$ versus $1.5 \%$ for females; $p<0.001)$ and absence of stressful periods $(3.7 \%$ versus $1.9 \%$ for males and $4.0 \%$ versus $1.5 \%$ for females; $p<0.001)$ at work or at home over the last year, while more non-migrants reported having felt some (54.3\% versus $38.3 \%$ for males and $55.0 \%$ versus $35.6 \%$ for females; $p<0.001$ ) or several periods of stress at work or at home (13.2\% versus $8.4 \%$ for males and $15.2 \%$ versus $12.2 \%$ for females; $p<0.001)$. Among migrant females, no association between stress at work or at home and BMI or WC was found, even after adjusting for other factors. Among migrant males, a weak positive association of stress at work or at home with BMI was observed in model $2(\beta=0.28,95 \%$ CI $0.00-0.56)$ and with WC in model $4(\beta=0.84,95 \%$ CI 0.05-1.63). However, these differences disappeared after further adjustment for other factors. Among non-migrants, an increase in stress frequency at work or at home was associated with a significant decrease in BMI and WC for both males $(\beta=-0.66,95 \% \mathrm{CI}-1.03$ to $-0.28 ; \beta=-1.7195 \%$ CI -2.69 to -0.73 , respectively $)$ and females $(\beta=-0.81$, $95 \% \mathrm{CI}-1.20$ to $-0.42 ; \beta=-1.46,95 \% \mathrm{CI}-2.30$ to -0.61 , respectively) even after adjusting for other factors.

\section{Negative life events}

Although a high percentage of non-migrants and migrants had experienced one or more negative life events within the past 12 months, the percentage was significantly higher in non-migrant males $(69.8 \%$ versus $59.6 \% ; p<0.001)$ and females $(68.0 \%$ versus $58.3 \%$; $p<0.001)$, compared with their migrant counterparts. However, negative life events were associated with BMI and WC among migrant males only, for whom the presence of a past negative event was associated with an increase in both BMI and WC $(\beta=0.78$, 95\% CI 0.34-1.22; $\beta=1.96$ 95\% CI 0.79-3.12, respectively). Among non-migrants and female migrants, negative life events were not significantly associated with BMI nor WC.

\section{Discussion}

\section{Key findings}

This study investigated associations between psychosocial stressors and BMI and WC in Ghanaian populations living in different contexts. Results differed based on stress factor, sex, and place of residence. Both the presence of one or more negative life event and stress at work or at home were positively associated with WC among male Ghanaian migrants in Europe. In contrast, stress at work or at home was negatively associated with BMI and WC in both female and male non-migrant Ghanaians. Other psychosocial stress factors revealed no significant associations.

\section{Interpretation of key findings}

In this study, we found that certain psychosocial stress factors were associated with BMI and WC in both migrant and non-migrant populations. However, the direction of the associations differed between migrant and non-migrant Ghanaians. Significant positive associations between negative life events as well as stress at work or at home and BMI and WC were found among Ghanaian migrant males. Among non-migrant Ghanaian males and females, however, stress at work and at home was negatively associated with BMI and WC. No associations were found in relation to perceived discrimination. Such variations in the associations of psychosocial stress factors with obesity could be expected, as the concept of stress includes many factors, which may be relevant or not, depending on the experiences of the population studied [30]. In fact, previous epidemiological studies, which examined factors such as job stress, childhood adversity, and caregiver stress, similarly found inconsistent associations of the stress variables with obesity [29].

Of the three psychosocial stress factors used in this study, negative life events were the most consistently associated with BMI and WC among male Ghanaian migrants. Despite a larger percentage of non-migrants having experienced one or more negative life event(s) within the past year, the association between negative life events and BMI and WC was observed in male migrants only. The explanations for these differential associations are unclear but may relate to factors such as perceived stress following the event, and behavioural response to the event. Firstly, it is possible that the degree of stress perceived following a negative life event is higher among migrants, who have added social and financial obligations to their family and friends back in Ghana [12]. For them, negative events such as unemployment or major illness may lead to concerns about fulfilling homeland obligations, as explained by Ghanaian migrants with hypertension in the Netherlands [12], and therefore increase the level of stress perceived following the event compared to non-migrants. This could in turn trigger a stronger physiological stress response, leading to weight change [21-25]. Perceived stress may also be higher among migrants due to personal frustrations following job or economic negative events. Indeed, migrants being on average more highly educated, may have higher job expectations and therefore increased stress and frustration when things go wrong. This is especially relevant in the context of Ghanaian migration 
to Europe, where "de-skilling" occurs regularly [46], leading to imbalances between expectations and reality that add stress to the migrant burden [47]. Secondly, it is possible that the European environment changes migrants' behavioural response to a negative life event stressor in such a way that obesity is favoured. Indeed, life events are often coped with by avoiding the problem, through unhealthy behavioural responses such as drinking, eating, or smoking more [48, 49]. Considering that smoking prevalence and alcohol consumption are significantly higher in Ghanaian migrants in Europe than in non-migrant Ghanaians in Ghana, as well as intake of unhealthy westernised foods [50], it is likely that a higher number of migrants respond to stressful life events by adopting aforementioned obesity-related behaviours. This holds particularly true for long-term migrants, seeing that acculturation and resulting dietary changes are processes, which occur over time. Although we controlled for acculturation in model 4 , the cultural orientation measure available focussed on the psychological aspects of acculturation rather than behavioural tendencies. Therefore, to assess whether behavioural responses to stress are indeed responsible for differential associations between negative life events and BMI and WC among migrants and non-migrants, future studies should consider including a measure of healthrelated coping behaviours. One such example is the SelfRegulatory Coping Behaviors (SRCB) index used by Mezuk et al. which evaluates smoking, alcohol intake, dietary habits and exercise following a stressful event [51].

In terms of sex variations, the stronger associations of a psychosocial stress factor with obesity observed in migrant males compared to females were consistent with literature $[29,52]$. While the reasons behind these sex variations remain unclear, different hormonal responses to stressful situations are suggested to be involved [53-55]. Indeed, men have been shown to respond to stressful situations with an increased glucocorticoid response compared to women, even when the reported subjective stress was identical [53]. Therefore, male Ghanaian migrants who reported the same stressful life events as females may actually have been exposed to higher glucocorticoid levels, which are known to promote energy storage as fat, affect food reward value typically increasing appetite, and have been associated with increased likelihoods of obesity $[25,26,56]$. Another hypothesis relates to the differential experiences male and female migrants may have in the host country, due to the intersection of their social identities and roles. Although both genders migrate to Europe primarily for work motives, many more Ghanaian females than males migrate for family reunion [57], and may therefore not have as much financial pressure as males migrating purely for economic reasons. Furthermore, Ghanaian gender norms place high expectations on men as the financial providers for the family [58]. Male migrants may thus have higher level of pre-existing socially dictated responsibilities, which, when combined with negative life events, could lead to added stress and thus more weight gain compared to females.

In the case of perceived discrimination, no associations with BMI and WC were found among Ghanaians in Europe or Ghana. These results are consistent with studies of migrants in The Netherlands, which found no evidence for an association between discrimination and obesity among Ghanaians, although other ethnic groups showed significant positive associations $[59,60]$. A potential explanation for the lack of association between discrimination and obesity is the strong social support and intragroup cohesion demonstrated by Ghanaians at home as well as in the Netherlands and the UK $[13,61]$, traits which have previously been found to attenuate associations between discrimination and ill health [62]. It is therefore possible that Ghanaians' strong community orientation acts as a buffer against the negative consequences of discrimination on health [60].

Stress at home or at work was weakly associated with an increase in BMI and $\mathrm{WC}$ in the male migrant population and strongly associated with a decrease in BMI and WC in the non-migrant population. These differences between populations are representative of previous literature focusing on stress at work, which show inconsistent positive associations between stress and BMI and WC [28, 30, 63, 64]. In a literature review of 10 cross-sectional studies, the authors found no support for an association between psychological workload and body weight or fat distribution [63]. Similarly, a cross-sectional study of female and male Finnish public sector workers examining higher job strain, lower job control, and higher effort-reward imbalance found only weak positive associations with BMI [28]. In contrast with these findings, a longitudinal study of the Whitehall II cohort of London-based workers showed that greater exposure to work stress over 19 years was linked to a significantly higher likelihood of general and abdominal obesity [64]. For Ghanaian migrants, who have recurrently reported working and living conditions as stressors [14], a longitudinal study such as the one performed with the Whitehall cohort may therefore be required to uncover consistent associations between stress at home or at work and general or abdominal obesity.

More striking are the strong negative associations between stress at home and at work and BMI and WC reported among the non-migrant Ghanaian population. Such negative tendencies were apparent with all three stress factors, but so far not significant. Although unexpected, these results are congruent with findings from a study performed in Ghana, which investigated relations between diet, stress, and chronic diseases, and concluded that more anxious males had, on average, lower body fat [65]. A similar inverse trend in Ghana compared to high-income countries has been observed previously, between socioeconomic position and obesity [66]. In high-income countries, lower socioeconomic 
position is associated with higher obesity, while in some low and middle-income countries such as Ghana, lower socioeconomic position is linked to lower obesity levels $[66,67]$. This is explained by wealthier people adopting unhealthy Western diets and exercising less, while individuals with a lower socioeconomic position do not have access to the same food choices [66, 67]. In fact, some non-migrant Ghanaians suffer from food insecurity, which has been shown to significantly augment their perceived psychological stress levels while decreasing their caloric intake $[68,69]$. It is therefore possible that lack of food access due to a low income is at least partially responsible for higher levels of stress being associated with lower adiposity among non-migrant Ghanaians. Following migration to Europe, environmental changes lead to a wider variety of food on offer, including unhealthy westernised energy-dense foods high in fat and sugar consumed more frequently by migrant Ghanaians in Europe than by non-migrants in Ghana [50]. These types of food are also preferred during periods of stress [56], which could possibly explain why Ghanaian migrants in Europe gain more weight when exposed to psychosocial stress factors than non-migrant Ghanaians.

\section{Strengths and limitations}

A main strength of this study is the use of four stress measures applicable and comparable among Ghanaians in Europe and Ghana to account for different aspects of stress, including perceived discrimination and more objective measurements such as negative life events. Furthermore, this study was based on a large homogenous sample of Ghanaians living in different locations, and data were collected according to standardized protocols across sites. However, several limitations should be considered. First, this study being cross-sectional, associations between stress and obesity pre-migration were not measured in the migrant population; thus, to understand the impact of migration on these associations, we are limited to comparing migrants to non-migrant Ghanaians, who may not respond to stress in exactly the same way. Second, also due to the cross-sectional design, the duration of stressors was not accounted for and the effects of chronic and acute stress on BMI and WC were therefore not differentiated, which may have attenuated the results. Third, all measures of stress were self-reported and thus subject to reporting bias. No objective physiological measure of stress such as cortisol levels was available, which could have revealed different associations. Fourth, several covariates were not accounted for in this study, such as income, food availability and prices. Thus, we cannot exclude the possibility of these variables influencing associations between psychosocial stress and BMI and WC. Fifth, most migrants included in the study were long-term migrants. We are therefore unable to comment on associations between psychosocial stress and BMI and WC among short-term migrant populations. Finally, despite efforts made during data collection, psychosocial stress measures in particular revealed different numbers of missing values in Europe and Ghana, which may have affected the validity of our results. Notwithstanding, these results provide novel insight into how stress may differentially affect obesity among migrating and non-migrating populations.

\section{Conclusions}

This study is the first to our knowledge to explore associations between psychosocial stress and obesity among SSA migrants in Europe and their non-migrant peers in Africa. We found significant associations in both populations; however, these differed in direction. Such findings suggest that the European context promotes an obesogenic stress response among male migrants, which is likely related to an increased intake of unhealthy westernised foods. Future research should therefore aim to establish causal connections between migration, stress, and adiposity using a longitudinal approach, to help further understand the origins of high obesity rates among migrants in Europe.

Funding This work was supported by the European Commission under the Framework Programme (Grant Number: 278901). Liam Smeeth was supported by the Wellcome Trust (grant number WT082178).

Open Access This article is distributed under the terms of the Creative Commons Attribution 4.0 International License (http://creativeco mmons.org/licenses/by/4.0/), which permits unrestricted use, distribution, and reproduction in any medium, provided you give appropriate credit to the original author(s) and the source, provide a link to the Creative Commons license, and indicate if changes were made.

\section{Appendix 1}

The Everyday Discrimination Scale (EDS) used in RODAM

\begin{tabular}{|c|c|c|c|c|c|}
\hline $\begin{array}{l}\text { In your daily } \\
\text { life, how } \\
\text { often have } \\
\text { the follow- } \\
\text { ing events } \\
\text { happened to } \\
\text { you because } \\
\text { of your } \\
\text { background? }\end{array}$ & Never (1) & $\begin{array}{l}\text { Hardly } \\
\text { ever } \\
(2)\end{array}$ & $\begin{array}{l}\text { Not too } \\
\text { often } \\
\text { (3) }\end{array}$ & $\begin{array}{l}\text { Fairly } \\
\text { often } \\
\text { (4) }\end{array}$ & Very often (5) \\
\hline $\begin{array}{l}\text { a. You're } \\
\text { treated } \\
\text { with less } \\
\text { courtesy }\end{array}$ & $\square$ & $\square$ & $\square$ & $\square$ & $\square$ \\
\hline
\end{tabular}




\begin{tabular}{|c|c|c|c|c|c|}
\hline $\begin{array}{l}\text { In your daily } \\
\text { life, how } \\
\text { often have } \\
\text { the follow- } \\
\text { ing events } \\
\text { happened to } \\
\text { you because } \\
\text { of your } \\
\text { background? }\end{array}$ & Never (1) & $\begin{array}{l}\text { Hardly } \\
\text { ever } \\
(2)\end{array}$ & $\begin{array}{l}\text { Not too } \\
\text { often } \\
(3)\end{array}$ & $\begin{array}{l}\text { Fairly } \\
\text { often } \\
(4)\end{array}$ & Very often (5) \\
\hline $\begin{array}{l}\text { b. You're } \\
\text { treated } \\
\text { with less } \\
\text { respect }\end{array}$ & $\square$ & $\square$ & $\square$ & $\square$ & $\square$ \\
\hline $\begin{array}{l}\text { c. You } \\
\text { receive } \\
\text { poorer } \\
\text { service } \\
\text { than other } \\
\text { people (in } \\
\text { restaurants } \\
\text { or shops) }\end{array}$ & $\square$ & $\square$ & $\square$ & $\square$ & $\square$ \\
\hline $\begin{array}{l}\text { d. People } \\
\text { act like } \\
\text { they think } \\
\text { you're not } \\
\text { smart }\end{array}$ & $\square$ & $\square$ & $\square$ & $\square$ & $\square$ \\
\hline $\begin{array}{l}\text { e. People act } \\
\text { like they're } \\
\text { afraid of } \\
\text { you }\end{array}$ & $\square$ & $\square$ & $\square$ & $\square$ & $\square$ \\
\hline $\begin{array}{l}\text { f. People } \\
\text { act like } \\
\text { they think } \\
\text { you're } \\
\text { dishonest }\end{array}$ & $\square$ & $\square$ & $\square$ & $\square$ & $\square$ \\
\hline $\begin{array}{l}\text { g. People act } \\
\text { like they're } \\
\text { better than } \\
\text { you are }\end{array}$ & $\square$ & $\square$ & $\square$ & $\square$ & $\square$ \\
\hline $\begin{array}{l}\text { h. You're } \\
\text { called } \\
\text { names or } \\
\text { insulted }\end{array}$ & $\square$ & $\square$ & $\square$ & $\square$ & $\square$ \\
\hline $\begin{array}{l}\text { i. You're } \\
\text { threatened } \\
\text { or harassed }\end{array}$ & $\square$ & $\square$ & $\square$ & $\square$ & $\square$ \\
\hline
\end{tabular}

\section{Appendix 2}

Psychological stress scale used in RODAM
In the past 12 months, have you felt stressed (feeling irritable or anxious or having trouble sleeping) because of the situation at work? $\square$ Never

$\square$ Some periods $\square$ Several periods $\square$ Constantly $\square$ Doesn't apply
In the past 12 months, have you felt stressed (feeling irritable or anxious or having trouble sleeping) because of the situation at home? $\square$ Never

$\square$ Some periods

$\square$ Several periods $\square$ Constantly

\section{Appendix 3}

List of Threatening Experiences (LTE) used in RODAM

We will now mention some events. Please indicate whether No Yes you've experienced these events in the past 12 months

a. You suffered from a serious illness or injury

b. A close relative had a serious illness or injury

c. Your parent, child, brother, sister, or spouse died

d. Another relative (such as an aunt, cousin, or grandparent) or close friend died

e. You broke off a steady relationship

f. A long-term friendship with a good friend or family member was broken off

g. You had a serious problem with a good friend, family member, or neighbour

h. You were sacked from your job or became unemployed

i. You had a major financial crisis

\section{References}

1. Di Cesare M, Bentham J, Stevens GA, Zhou B, Danaei G, Lu Y et al (2016) Trends in adult body-mass index in 200 countries from 1975 to 2014: a pooled analysis of 1698 population-based measurement studies with 19.2 million participants. Lancet 387:1377-1396

2. Misra A, Ganda OP (2007) Migration and its impact on adiposity and type 2 diabetes. Nutrition 23:696-708

3. Labree LJ, van de Mheen HD, Rutten FF, Foets MM (2011) Differences in overweight and obesity among children from migrant and native origin: a systematic review of the European literature. Obes Rev 12:e535-e547

4. Agyemang C, Addo J, Bhopal R, de Aikins GA, Stronks K (2009) Cardiovascular disease, diabetes and established risk factors among populations of sub-Saharan African descent in Europe: a literature review. Glob Health 5:7

5. Agyemang C, Meeks KA, Beune EJ, Owusu-Dabo E, Mockenhaupt FP, Addo J et al (2016) Obesity and type 2 diabetes in sub-Saharan Africans-is the burden in today's Africa similar to African migrants in Europe? The RODAM study. BMC Med 14:166

6. Meeks KA, Freitas-Da-Silva D, Adeyemo A, Beune EJ, Modesti PA, Stronks K et al (2015) Disparities in type 2 diabetes prevalence among ethnic minority groups resident in Europe: a systematic review and meta-analysis. Intern Emerg Med 11:327-340

7. Agyemang C, Beune EJ, Meeks KA, Owusu-Dabo E, AgyeiBaffour P, de Aikins A et al (2014) Rationale and crosssectional study design of the research on obesity and type 2 
diabetes among African Migrants: the RODAM study. BMJ Open 4:e004877-e004877

8. NHS Health and Social Care Information Centre (2005) Health Survey for England 2004. The health of minority ethnic groupsheadline tables. NHS Health and Social Care Information Centre, Public Health Statistics, London

9. Agyemang C, de Munter J, van Valkengoed I, van den Born B-J, Stronks K (2008) Gender disparities in hypertension among different ethnic groups in Amsterdam, The Netherlands: the SUNSET study. Am J Hypertens 21:1001-1006

10. Gonzalez-Garcia M, Hitaj ME, Mlachila MM, Viseth A, Yenice M (2016) Sub-Saharan African migration: patterns and spillovers. International Monetary Fund Spill Over Notes, Washington DC

11. Kopelman PG (2000) Obesity as a medical problem. Nature 404:635-643

12. Beune EJ, Haafkens JA, Schuster JS, Bindels PJ (2006) "Under pressure": how Ghanaian, African-Surinamese and Dutch patients explain hypertension. J Hum Hypertens 20:946-955

13. Knipscheer J, Kleber R (2007) Acculturation and mental health among Ghanaians in the Netherlands. Int J Soc Psychiatry 53:369-383

14. Boateng L, Nicolaou M, Dijkshoorn H, Stronks K, Agyemang C (2012) An exploration of the enablers and barriers in access to the Dutch healthcare system among Ghanaians in Amsterdam. BMC Health Serv Res 12:75

15. Stanner S (2001) Health Survey for England 1999: the health of minority ethnic groups. Nutr Bull 26:227-230

16. Viruell-Fuentes EA, Miranda PY, Abdulrahim S (2012) More than culture: structural racism, intersectionality theory, and immigrant health. Soc Sci Med 75:2099-2106

17. Lazarus RS, Folkman S (1984) Stress, appraisal, and coping. Springer Publishing Company, New York

18. Folkman S (2012) The Oxford handbook of stress, health, and coping. Oxford University Press, Oxford

19. Aldwin CM (2007) Stress, coping, and development: an integrative perspective. Guilford Press, New York

20. Segerstrom SC, O'Connor DB (2012) Stress, health and illness: four challenges for the future. Psychol Health 27:128-140

21. Sherwood L (2015) Human physiology: from cells to systems, 9th edn. Brooks/Cole, Belmont

22. Spencer SJ, Tilbrook A (2011) The glucocorticoid contribution to obesity. Stress 14:233-246

23. Sinha R, Jastreboff AM (2013) Stress as a common risk factor for obesity and addiction. Biol Psychiatry 73:827-835

24. Foss B, Dyrstad SM (2011) Stress in obesity: cause or consequence? Med Hypotheses 77:7-10

25. Scott KA, Melhorn SJ, Sakai RR (2012) Effects of chronic social stress on obesity. Curr Obes Rep 1:16-25

26. Adam TC, Epel ES (2007) Stress, eating and the reward system. Physiol Behav 91:449-458

27. Gibson EL (2006) Emotional influences on food choice: sensory, physiological and psychological pathways. Physiol Behav 89:53-61

28. Kouvonen A, Kivimaki M, Cox SJ, Cox T, Vahtera J (2005) Relationship between work stress and body mass index among 45,810 female and male employees. Psychosom Med 67:577-583

29. Wardle J, Chida Y, Gibson E, Whitaker K, Steptoe A (2011) Stress and adiposity: a meta-analysis of longitudinal studies. Obesity 19:771-778

30. Rosengren A, Hawken S, Ôunpuu S, Sliwa K, Zubaid M, Almahmeed WA et al (2004) Association of psychosocial risk factors with risk of acute myocardial infarction in 11119 cases and 13 648 controls from 52 countries (the INTERHEART study): casecontrol study. Lancet 364:953-962

31. Haregu TN, Oti S, Egondi T, Kyobutungi C (2016) Measurement of overweight and obesity an urban slum setting in sub-Saharan
Africa: a comparison of four anthropometric indices. BMC Obes 3:46

32. World Health Organization (2011) Waist circumference and waisthip ratio: report of a WHO expert consultation Geneva, 8-11 December 2008. WHO, Geneva

33. Essed P (1991) Understanding everyday racism: an interdisciplinary theory. Sage, Beverly Hills

34. Williams DR, Yu Y, Jackson JS, Anderson NB (1997) Racial differences in physical and mental health: socio-economic status, stress and discrimination. J Health Psychol 2:335-351

35. Peek ME, Nunez-Smith M, Drum M, Lewis TT (2011) Adapting the everyday discrimination scale to medical settings: reliability and validity testing in a sample of African American patients. Ethn Dis 21:502-509

36. Pérez DJ, Fortuna L, Alegría M (2008) Prevalence and correlates of everyday discrimination among U.S. Latinos. J Community Psychol 36:421-433

37. Lewis TT, Everson-Rose SA, Powell LH, Matthews KA, Brown C, Karavolos K et al (2006) Chronic exposure to everyday discrimination and coronary artery calcification in African-American women: the SWAN Heart Study. Psychosom Med 68:362-368

38. Ikram UZ, Snijder MB, Fassaert TJL, Schene AH, Kunst AE, Stronks K (2015) The contribution of perceived ethnic discrimination to the prevalence of depression. Eur J Public Health 25:243-248

39. Rosmalen JG, Bos EH, de Jonge P (2012) Validation of the Long-term Difficulties Inventory (LDI) and the list of threatening experiences (LTE) as measures of stress in epidemiological population-based cohort studies. Psychol Med 42:2599-2608

40. Brugha T, Bebbington P, Tennant C, Hurry J (1985) The list of threatening experiences: a subset of 12 life event categories with considerable long-term contextual threat. Psychol Med 15:189-194

41. Kroenke K, Spitzer RL, Williams JB, Löwe B (2010) The Patient Health Questionnaire somatic, anxiety, and depressive symptom scales: a systematic review. Gen Hosp Psychiatry 32:345-359

42. Tropp LR, Erkut S, Coll CG, Alarcón O, García HAV (1999) Psychological acculturation: development of a new measure for Puerto Ricans on the U.S. mainland. Educ Psychol Meas 59:351-367

43. Levecque K, van Rossem R (2014) Depression in Europe: does migrant integration have mental health payoffs? A cross-national comparison of 20 European countries. Ethn Health 20:49-65

44. Selten JP, Laan W, Kupka R, Smeets HM, van Os J (2012) Risk of psychiatric treatment for mood disorders and psychotic disorders among migrants and Dutch nationals in Utrecht, The Netherlands. Soc Psychiatry Psychiatr Epidemiol 47:271-278

45. Rivera B, Casal B, Currais L (2015) Length of stay and mental health of the immigrant population in Spain: evidence of the healthy immigrant effect. Appl Econ 47:1972-1982

46. Black R, Quartey P, Castagnone E, Nazio T, Schoumaker B, Rakotonarivo A (2018) Ghanaian migration: economic participation. In: Beauchemin C (ed) Migration between Africa and Europe. Springer International Publishing, Cham, pp 291-317

47. Siar SV (2013) From highly skilled to low skilled: revisiting the deskilling of migrant labor. PIDS discuss pap ser

48. Billings AG, Moos RH (1981) The role of coping responses and social resources in attenuating the stress of life events. J Behav Med 4:139-157

49. José BS, van Oers HA, van de Mheen HD, Garretsen HF, Mackenbach JP (2000) Stressors and alcohol consumption. Alcohol Alcohol 35:307-312

50. Galbete C, Nicolaou M, Meeks KA, de-Graft Aikins A, Addo J, Amoah SK et al (2017) Food consumption, nutrient intake, and dietary patterns in Ghanaian migrants in Europe and their compatriots in Ghana. Food Nutr Res 61:1341809 
51. Mezuk B, Ratliff S, Concha JB, Abdou CM, Rafferty J, Lee H et al (2017) Stress, self-regulation, and context: evidence from the health and retirement survey. SSM Popul Health 3:455-463

52. Korkeila M, Kaprio J, Rissanen A, Koskenvuo M, Sörensen TI (1998) Predictors of major weight gain in adult Finns: stress, life satisfaction and personality traits. Int J Obes 22:949-957

53. Reschke-Hernández AE, Okerstrom KL, Bowles Edwards A, Tranel D (2017) Sex and stress: men and women show different cortisol responses to psychological stress induced by the Trier social stress test and the Iowa singing social stress test. J Neurosci Res 95:106-114

54. Kirschbaum C, Wüst S, Hellhammer D (1992) Consistent sex differences in cortisol responses to psychological stress. Psychosom Med 54:648-657

55. Kudielka BM, Kirschbaum C (2005) Sex differences in HPA axis responses to stress: a review. Biol Psychol 69:113-132

56. Torres SJ, Nowson CA (2007) Relationship between stress, eating behavior, and obesity. Nutrition 23:887-894

57. Schans D, Mazzucato V, Schoumaker B, Flahaux M-L (2013) Changing patterns of Ghanaian migration. In: Beauchemin $\mathrm{C}$ (ed) Migration between Africa and Europe. Springer, Cham, pp 265-289

58. Adinkrah M (2012) Better dead than dishonored: masculinity and male suicidal behavior in contemporary Ghana. Soc Sci Med 74:474-481

59. Agyei B, Nicolaou M, Boateng L, Dijkshoorn H, van den Born B-J, Agyemang C (2014) Relationship between psychosocial stress and hypertension among Ghanaians in Amsterdam, the Netherlands - the GHAIA study. BMC Public Health 14:692

60. Schmengler H, Ikram UZ, Snijder MB, Kunst AE, Agyemang C (2017) Association of perceived ethnic discrimination with general and abdominal obesity in ethnic minority groups: the HELIUS study. J Epidemiol Community Health 71:453-460
61. Vasta E, Kandilige L (2010) "London the Leveller": Ghanaian work strategies and community solidarity. J Ethn Migr Stud 36:581-598

62. Pascoe EA, Richman LS (2009) Perceived discrimination and health: a meta-analytic review. Psychol Bull 135:531-554

63. Overgaard D, Gyntelberg F, Heitman BL (2004) Psychological workload and body weight: is there an association? A review of the literature. Occup Med 54:35-41

64. Brunner EJ, Chandola T, Marmot MG (2007) Prospective effect of job strain on general and central obesity in the Whitehall II Study. Am J Epidemiol 165:828-837

65. Mohammed H, Ghosh S, Vuvor F, Mensah-Armah S, SteinerAsiedu M (2016) Dietary intake and the dynamics of stress, hypertension and obesity in a periurban community in Accra. Ghana Med J 50:16-21

66. Akinyemiju TF, Zhao X, Sakhuja S, Jolly P (2016) Life-course socio-economic status and adult BMI in Ghana; analysis of the WHO study on global ageing and adult health (SAGE). Int J Equity Health 15:185

67. Addo J, Agyemang C, de-Graft Aikins A, Beune EJ, Schulze MB, Danquah I et al (2017) Association between socioeconomic position and the prevalence of type 2 diabetes in Ghanaians in different geographic locations: the RODAM study. J Epidemiol Community Health 71:633-639

68. Atuoye KN, Luginaah I (2017) Food as a social determinant of mental health among household heads in the Upper West Region of Ghana. Soc Sci Med 180:170-180

69. Addo AA, Marquis GS, Lartey AA, Pérez-Escamilla R, Mazur RE, Harding KB (2011) Food insecurity and perceived stress but not HIV infection are independently associated with lower energy intakes among lactating Ghanaian women. Matern Child Nutr 7:80-91

\section{Affiliations}

\section{Clarissa Baratin ${ }^{1,2} \cdot$ Erik Beune $^{1} \cdot$ Daan van Schalkwijk ${ }^{2} \cdot$ Karlijn Meeks $^{1} \cdot$ Liam Smeeth $^{3} \cdot$ Juliet Addo $^{3}$. Ama de-Graft Aikins ${ }^{4}$. Ellis Owusu-Dabo ${ }^{5}$. Silver Bahendeka ${ }^{6}$. Frank P. Mockenhaupt ${ }^{7} \cdot$ Ina Danquah $^{8,9}$. Matthias B. Schulze ${ }^{8} \cdot$ Joachim Spranger ${ }^{10,11} \cdot$ Daniel Boateng $^{12} \cdot$ Kerstin Klipstein-Grobusch $^{12,13} \cdot$ Karien Stronks $^{1}$. Charles Agyemang ${ }^{1}$}

1 Department of Public Health, Amsterdam Academic Medical Center, University of Amsterdam, Amsterdam Public Health Research Institute, Meibergdreef 9, 1105 AZ Amsterdam, The Netherlands

2 Amsterdam University College, Amsterdam, The Netherlands

3 Department of Non-communicable Disease Epidemiology, London School of Hygiene and Tropical Medicine, London, UK

4 Regional Institute for Population Studies, University of Ghana, Legon, Ghana

5 School of Public Health, Kwame Nkrumah University of Science and Technology, Kumasi, Ghana

6 MKPGMS-Uganda Martyrs University, Kampala, Uganda

7 Institute of Tropical Medicine and International Health, Charité-University Medicine Berlin, Augustenburger Platz 1, 13353 Berlin, Germany

8 Department of Molecular Epidemiology, German Institute of Human Nutrition Potsdam-Rehbrücke, Arthur-Scheunert-Allee 114-116, 14558 Nuthetal, Germany
9 Institute for Social Medicine, Epidemiology and Health Economics, Charité-Universitätsmedizin Berlin, Corporate Member of Freie Universität Berlin, Humboldt-Universitaet zu Berlin, and Berlin Institute of Health, Berlin, Germany

10 Department of Endocrinology and Metabolism, DZHK (German Centre for Cardiovascular Research), Partner Site Berlin, Berlin, Germany

11 Center for Cardiovascular Research (CCR), Charite Universitätsmedizin Berlin Charite Center for Cardiovascular Research (CCR), Berlin, Germany

12 Julius Global Health, Julius Center for Health Sciences and Primary Care, University Medical Center Utrecht, Utrecht University, Utrecht, The Netherlands

13 Division of Epidemiology and Biostatistics, School of Public Health, Faculty of Health Sciences, University of the Witwatersrand, Johannesburg, South Africa 